\title{
A Constituição do Perito Psicólogo em Varas de Família à Luz da Análise Institucional de Discurso
}

\author{
The Constitution Of Psychology Expert \\ Witness In Family Courts In The Lights Of \\ Institutional Discourse Analysis \\ La Constitución Del Experto Psicólogo En \\ Juzgados De Familia A La Luz Del \\ Análisis Institucional De Discurso
}

Marta Cristina Meirelles Ortiz

Universidade Federal de São Paulo

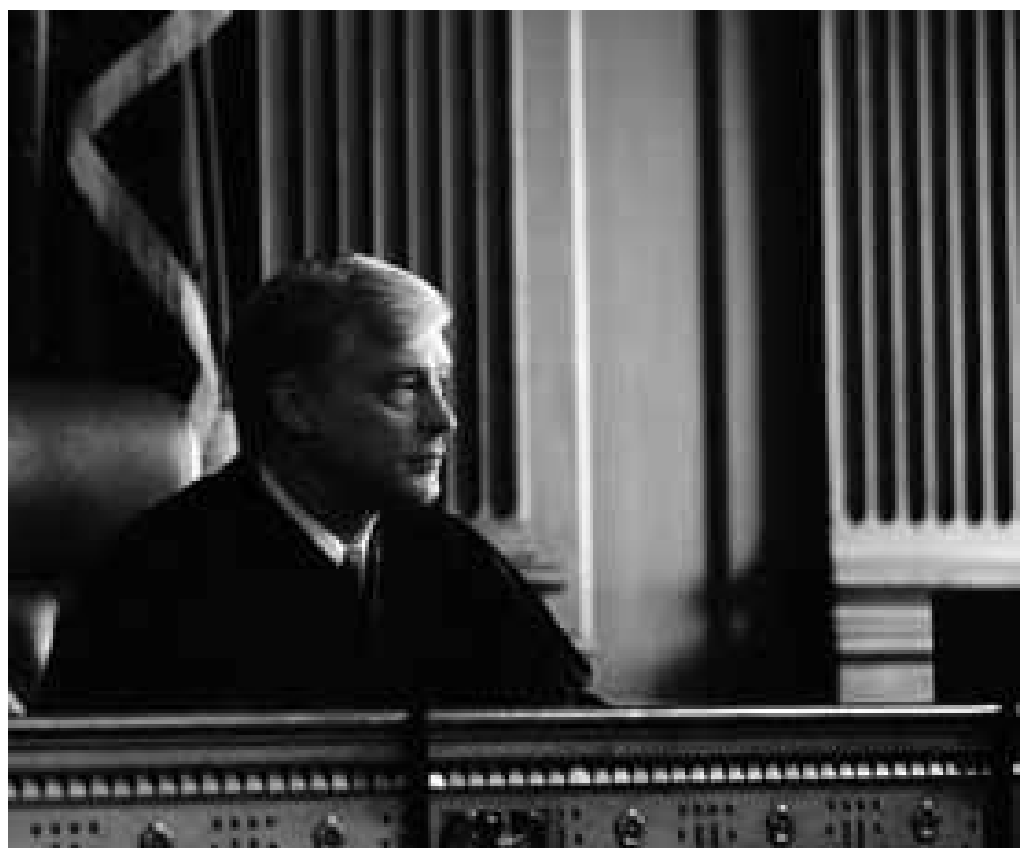


Resumo: O processo judicial impõe ao conflito familiar uma forma triangular, constituída de duas partes litigantes que demandam a decisão de um terceiro, o juiz. A análise institucional do discurso, por meio de suas concepções de discurso, de sujeito, de instituição e de transferência, contribui para melhor compreensão do lugar do perito-psicólogo na cena processual configurada pela instituição judiciária e para um debate mais consistente sobre os diversos fatores implicados em suas ações. Por meio dela, podemos compreender como se constitui o perito psicólogo a partir da triangulação configurada no processo e a importância da análise da transferência processual. A leitura crítica dos autos é o primeiro passo dessa análise, e contribui para posicionar o perito em relação à demanda da instituição. A entrevista, que coloca o perito em contato direto com os litigantes, evidencia a relação de exterioridade que, não obstante demandado pelo processo, o saber psicológico mantém em relação ao Direito. Expectativas e afetos, bem como possíveis efeitos subjetivos da relação com o perito, devem ser considerados. O laudo é o momento em que o perito psicólogo toma a palavra no processo judicial e tem um caráter interventivo. A perícia, como prova judicial, afirma-se em uma certa vontade de verdade característica da instituição jurídica e, ao mesmo tempo, na intenção do perito de, como coadjuvante da cena processual, nela produzir efeitos singulares. É importante que se reconheça que o que se produz na perícia judicial não é a Verdade, mas uma verdade relativa, a atribuição de um sentido possível ao conflito configurado no processo.

Palavras-chave: Análise do discurso. Análise institucional. Perícia psicológica judicial. Psicologia forense.

\begin{abstract}
The judicial process imposes on family dispute a triangular shape, constituting two litigant parties that require a decision by a third one, the judge. Institutional discourse analysis, by its conception of discourse, subject, institution and transference, contributes to a better understanding of the psychology expert witnesses place at the scene set by the judicial proceedings, and for a more consistent discussion on the various factors involved in their actions. Through it, we can understand how the psychology expert witness is constituted in the triangulation configured in the proceedings and the importance of the analysis of procedural transference. The critical reading of the file is the first step of the analysis, helping to position the expert concerning the demand of the institution. The interview, which puts the expert in direct contact with the litigants, shows the exteriority relations that, despite demanded by the process, the psychological knowledge maintains with the law. Expectations and affects, as well as possible subjective effects of the relation with the expert, must be considered. The report is the moment when the psychology expert witness speaks in the proceedings, what has an interventional character. The expertise, as a judicial proof, is based on a certain will of truth, characteristic of the juridical institution and, at the same time, on the intention of the expert, as a supporting actor in the proceedings scene, to produce in it singular effects. It is important to recognize that what is produced in judicial expertise is not the Truth, but a relative truth that gives a possible meaning to the conflict configured in the judicial process.
\end{abstract}

Keywords: Discourse analysis. Institutional discourse analysis. Forensic psychological examination. Forensic psychology.

Resumen: El proceso judicial le impone al conflicto familiar una forma triangular, constituida de dos partes litigantes que demandan la decisión de un tercero, el juez. El análisis institucional del discurso, por medio de sus concepciones de discurso, de sujeto, de institución y de transferencia, contribuye para una mejor comprensión del lugar del experto psicólogo en la escena procesal configurada por la institución judiciaria y para un debate más consistente sobre los diversos factores implicados en sus acciones. Por medio de ella, podemos comprender como se constituye el experto psicólogo desde la triangulación configurada en el proceso y la importancia del análisis de la transferencia procesal. La lectura crítica de los autos es el primer paso de ese análisis, y contribuye para posicionar al perito en relación a la demanda de la institución. La entrevista, que coloca el perito en contacto directo con los litigantes, evidencia la relación de exterioridad que, no obstante demandado por el proceso, el saber psicológico mantiene con relación al Derecho. Expectativas y afectos, así como posibles efectos subjetivos de la relación con el experto, deben ser considerados. El laudo es el momento en el que el experto psicólogo toma la palabra en el proceso judicial y tiene un carácter interventor. La pericia, como prueba judicial, se afirma en una cierta voluntad de verdad característica de la institución jurídica y, al mismo tiempo, en la intención del experto de, como coadyuvante de la escena procesal, en ella producir efectos singulares. Es importante que se reconozca que lo que se produce en la pericia judicial no es la Verdad, sino una verdad relativa, la atribución de un sentido posible al conflicto configurado en el proceso.

Palabras clave: Análisis del discurso. Análisis institucional. Pericia psicológica judicial. Psicologia Forense. 
A forma pela qual se dá a constituição do psicólogo na função de perito no contexto de processos de Varas de Família merece uma reflexão acurada. De modo geral, ela se dá no entrecruzamento de pelo menos três ordens distintas de conflito: a primeira diz respeito à dissensão familiar que deu origem ao processo; a segunda se refere ao encontro nem sempre pacífico entre duas disciplinas distintas: a Psicologia e o Direito; a terceira, finalmente, é aquela que envolve a complexidade inerente ao exercício de nossa profissão como psicólogos em qualquer lugar que ele aconteça. É, portanto, em meio a diversas linhas de combate que se encontra o perito, e é isso que torna necessário pensar de modo estratégico como se dá a sua entrada na cena processual.

O processo judicial impõe ao conflito familiar uma triangulação, constituída de duas partes litigantes que demandam a decisão de um terceiro, o juiz. A função social desse arranjo, supõe-se, é a pacificação social e a promoção da Justiça por meio de uma douta discussão com bases legais.

No presente texto, partimos do pressuposto de que essa triangulação gera certos modos de constituição subjetiva que são próprios à instituição judiciária. Portanto, na transformação do drama familiar em processo judicial, o conflito privado assume uma forma pública, dando a seus atores novos lugares em outra cena, marcada por disposições um tanto diferentes da original.

A relevância de se discutir a constituição do perito psicólogo em Varas de Família e Sucessões se faz notar quando constatamos as tensões que se traduzem em uma crescente preocupação, por parte dos Conselhos Federal e Regionais de Psicologia, em promover debates e regulamentar as práticas psicológicas na instituição judiciária. Podemos destacar, como resultado desse movimento, as Referências Técnicas para Atuação do
Psicólogo em Varas de Família (Conselho Federal de Psicologia, 2010) e a Resolução no 08/2010, do Conselho Federal de Psicologia, sobre a participação do psicólogo como perito e assistente técnico no Poder Judiciário. Outra produção recente de interesse nessa área é o Caderno Temático 10 (2010), publicado pelo Conselho Regional de Psicologia da 6‥ Região, que contém uma coletânea de trabalhos apresentados em eventos diversos sob o título Psicólogo judiciário nas Varas de Família. A ética própria da psicologia: mudanças nas relações assistente técnico e perito.

Em suas considerações iniciais, a Resolução no 08/2010 menciona a necessidade de o psicólogo

levar em conta as relações de poder nos contextos em que atua e os impactos dessas relações sobre suas atividades profissionais, posicionando-se de forma crítica e em consonância com os demais princípios do Código de Ética Profissional, conforme disposto no princípio fundamental VII, do Código de Ética Profissional

Acreditamos que um posicionamento crítico exija uma constante reflexão acerca das possibilidades e dos limites de nosso trabalho como peritos.

Partindo dessa preocupação é que propomos, como objetivo do presente trabalho, a discussão dos processos de subjetivação que ocorrem na constituição do peritopsicólogo nas Varas de Família e Sucessões, e escolhemos fazê-lo com base no método de análise institucional do discurso (AID) proposto por Marlene Guirado (2000, 2004, 2006, 2009, 2010). Pensamos que a AID tenha muito a contribuir para a melhor compreensão do lugar do perito-psicólogo na cena processual configurada pela instituição judiciária e para um debate mais consistente sobre os diversos fatores constituintes de suas ações, isso porque a análise institucional 
do discurso se posiciona radicalmente contra qualquer naturalização do discurso psicológico, considerando a Psicologia como instituição e os psicólogos como seus agentes. Podemos ainda dizer o mesmo sobre o discurso judiciário, que define o perito como um auxiliar da Justiça, um agente, portanto, da cena judicial. A prática da perícia passa a ser analisada, então, a partir desse duplo agenciamento.

O que buscamos, a partir da AID, é provocar e contribuir para uma reflexão mais ampliada e potente sobre esse tema. Antes, porém, é preciso tecer algumas considerações sobre o próprio método segundo sua autora, Marlene Guirado.

\section{Sobre a análise institucional do discurso (AID)}

Um dos diferenciais da AID, segundo Guirado, é o conceito de instituição com que se trabalha:

(...) conjunto de relações sociais que se repetem e, nessa repetição, se legitimam (...). Essa legitimação se dá, em ato, pelos efeitos de reconhecimento de que essas relações são óbvias e que naturalmente sempre foram assim. Dá-se, ao mesmo tempo e complementarmente, pelos efeitos de desconhecimento de sua relatividade. (...) O mais importante nessa compreensão de instituição é que ela nos coloca, na qualidade de agentes ou de clientela, como atores em cena. É a nossa ação que faz a instituição. (...) Assim, não há como se referir à instituição como um corpo estranho, acima de nossas cabeças, com vida própria e independente de nós. Nós a fazemos. E, mesmo que à revelia de nossa consciência, reconhecemos como natural e legítimo esse fazer. (2010, pp. 36- 37)

Partindo desse pressuposto, a Psicologia, considerada instituição do conhecimento e da prática profissional, é tomada, em seu exercício, "como discurso que produz e reproduz verdades, num jogo de forças poder- resistência" (Guirado, pp. 40, 41). Seu objeto é definido como:

(...) as relações, mas não aquelas imediatamente observáveis e sim, tal como percebidas, imaginadas, por aqueles que concretamente as fazem. O que caracteriza o especificamente humano e psicológico não são as habilidades e capacidades dos indivíduos, tomados como coisas em si, mas sim, o universo de suas representações e afetos, bem como sua inserção no discurso institucional. (Guirado, 2004, p. 113, grifos no original)

Guirado propõe como operador analítico a metáfora do sujeito-dobradiça. Tal metáfora diz respeito a um sujeito configurado a partir de relações institucionais articuladas e rearticuladas de modo singular desde o berço e ao longo de toda a sua história de vida, por meio de uma série de constantes reedições que acontecem na medida em que ele ocupa lugares distintos em instituições diversas como a família, a escola, a saúde, etc.

O campo privilegiado por meio do qual podemos estudar esse sujeito é o da intersubjetividade, configurada no e pelo discurso. Com base em Foucault, Guirado compreende o discurso como ato e como dispositivo institucional que produz, ao mesmo tempo, uma certa forma de relação e formas de ser sujeito. Esse pressuposto a aproxima da análise de discurso (AD) francesa, em sua vertente pragmática, e especialmente do trabalho do linguista francês Dominique Maingueneau.

Um dos conceitos-chaves que a $\mathrm{AD}$ empresta à AID é o de gênero discursivo, definido por Guirado como "dispositivo social que regula a produção e a recepção de discursos" e como "uma realidade empírica que é, ao mesmo tempo, uma organização verbal e um fenômeno social" (2010, p. 114). O gênero discursivo é constituinte do que Maingueneau denomina cena enunciativa, ou cenografia, que diz respeito, segundo Guirado, ao tipo 
de relação que cada discurso estabelece e na qual todos os interlocutores estão implicados.

Com base no que acaba de ser dito, deve-se reconhecer que o Direito, com seus códigos formais, organiza certas formas de pacificação de conflitos nas relações sociais, constituindo um gênero discursivo característico do processo judicial. Não podemos desconhecer, portanto, que é nessas e por essas relações que nos constituímos como peritos e é a partir delas que construímos o nosso fazer na cena processual. Isso não significa dizer que o psicólogo deva abrir mão do instrumental teórico e metodológico próprio à sua disciplina, mas que, de alguma forma, tal instrumental é colocado forçosamente a serviço de uma ordem que o extrapola.

Esse fato revela a importância da problematização do nosso lugar como peritos-psicólogos em relação às demandas da instituição judiciária. Sem isso, corremos o risco de, inadvertidamente, cedermos a uma naturalização do lugar que nos é atribuído por tal instituição, tornando nosso trabalho, ainda que eficiente segundo o que dele se espera, desprovido de qualquer caráter efetivamente crítico, instituinte ou transformador da realidade social da qual participamos.

Problematizar o lugar no qual somos colocados na cena processual, que se reedita a cada nova demanda judicial, implica lidarmos com processos subjetivos que afetam todos os seus atores, inclusive o perito. Faz sentido, portanto, falarmos de uma certa ordem de efeitos de subjetivação que acontecem nas relações entre perito, partes litigantes, seus advogados, assistentes técnicos, juiz e Ministério Público, explicitando que tais processos seriam da ordem da transferência.

Não se trata, evidentemente, de uma transferência tal qual ocorre em um consultório de psicanálise. De qualquer modo, esse fenômeno nos afeta a tal ponto que não podemos menosprezar seus efeitos, sem correr o risco de sermos por ele enlaçados. Retomada, porém, em seu potencial analítico, o conceito de transferência se transforma em importante instrumento a potencializar as práticas que são próprias à nossa profissão.

\section{A análise institucional do discurso e a transferência}

O conceito de transferência, desenvolvido por Freud, serviu para explicar e instrumentalizar um processo subjetivo observado por ele durante a análise de seus pacientes. Tal processo, quando ocorria durante a situação de análise, produzia efeitos capazes de desconcertar os próprios analistas. No artigo A dinâmica da transferência, ela foi definida como "a mais forte resistência ao tratamento" e, ao mesmo tempo, como "a mais forte alavanca do sucesso" do processo analítico (Freud, 1912/2010, p. 137). No mesmo texto, Freud afirma que a transferência ocorre a partir de relações anteriores, em geral ligadas a figuras significativas da infância, que são reeditadas na própria análise:

Tenhamos presente que todo ser humano, pela ação conjunta de sua disposição inata e de influências experimentadas na infância, adquire um certo modo característico de conduzir sua vida amorosa, isto é, as condições que estabelece para o amor, os instintos que satisfaz então, os objetivos que se coloca. Isso resulta, por assim dizer, num clichê (ou vários), que no curso da vida é regularmente repetido, novamente impresso, na medida em que as circunstâncias externas e a natureza dos objetos amorosos acessíveis o permitem, e que sem dúvida não é inteiramente imutável diante de impressões recentes. (...)

É perfeitamente normal e compreensível, portanto, que o investimento libidinal de uma pessoa em parte insatisfeita, mantido esperançosamente em prontidão, também se volte para a figura do médico. (Freud, 1912/2010, pp. 134-136) 
Guirado (2000,

2006) afirma que

a transferência,

tal como

observada,

estudada e

instrumentalizada

por Freud, é

constituída por

e constituinte de

um determinado

conjunto de

relações que

acontecem na

clínica analítica.
$1 \mathrm{Em}$ uma palestra proferida no Instituto de Psicologia da Universidade de São Paulo em 17 de maio de 1999,

Maingueneau usou a expressão "cena englobante" para se referir aos lugares socialmente definidos para que determinados discursos sejam enunciados, por exemplo: sala de aula, palanque, púlpito, consultório médico, etc.
Com base na análise institucional do discurso, Guirado (2000, 2006) afirma que a transferência, tal como observada, estudada e instrumentalizada por Freud, é constituída por e constituinte de um determinado conjunto de relações que acontecem na clínica analítica.

Para Guirado, as práticas da psicanálise, ao se repetirem e se legitimarem, configuram uma instituição. Por um lado, tais relações produzem determinados modos de subjetivação que ocorrem apenas na clínica psicanalítica, cuja cena englobante ${ }^{1}$ é o consultório. Por outro lado, essa autora aponta uma ampliação do conceito de transferência para além desse cenário:

Se considero não mais a clínica psicanalítica em si, mas o exercício da psicanálise no interior de uma outra instituição, os 'sujeitos' em transferência, os do campo transferencial, são sobredeterminados pelo conjunto dessa outra prática institucional. Não há como pensá-los sempre da mesma forma, numa ou noutra rede de relações. (...)

(...) a subjetividade com que se trabalha, no nível analítico ou terapêutico, no interior de instituições que não o consultório, é essa subjetividade a supor reedições de relações sobre um terreno já marcado por uma estrutura de lugares, um imaginário e um objeto que lhe são característicos. (Guirado, 1995/2006, pp. 119-120)

Ao falar da prática da psicanálise em outros âmbitos institucionais que não o consultório, Guirado problematiza a análise da transferência nesses contextos, amplificando e potencializando o alcance desse conceito. Tal ampliação acaba por incidir, em retorno, sobre o modo como se faz a clínica no consultório. Em sua tese de livre docência, $A$ análise institucional do discurso como analítica da subjetividade, Guirado esclarece: (...) "a transferência passa a ser pensada na superfície mesma da trama discursiva e isso (...) se torna possível porque trabalhamos com a idéia de lugares institucionais de enunciação e de contexto concreto para a subjetivação e a produção de sentidos (...)" (2009, p. 162).

A partir dessas considerações, voltamos ao tema proposto no início, ou seja, a prática da perícia psicológica no âmbito de relações configuradas na, e pela, instituição jurídica em processos de Varas de Família e passamos a pensar sobre a constituição do lugar do perito a partir de um tipo de transferência que lhe é característica. No próximo tópico, trataremos de elucidar o modo como isso efetivamente acontece.

\section{A constituição do perito}

A nós, psicólogos, as formas que demandas singulares adquirem no discurso jurídico podem causar certo estranhamento, parecendo muitas vezes um tanto bizarras e exageradas. Todavia, não podemos negar os efeitos retóricos desse discurso, por vezes aliciadores de nossa simpatia, por vezes causa de aversão. São efeitos que fazem lembrar Foucault, em A Vida dos Homens Infames (1977), ao analisar o discurso das petições escritas que pessoas do povo dirigiam ao Rei, no Estado Absolutista, para solicitar ordens de prisão:

As" ordens do rei" (...) eram solicitadas contra alguém por seus familiares (...); elas eram humilde e insistentemente solicitadas, como se se tratasse de algum grande crime que teria merecido a cólera do soberano, por alguma obscura história de família (...).

(...) Mas esse poder, é preciso ainda, ao menos por um instante, dele se apropriar, canalizá-lo, captá-lo e incliná-lo na direção que se quer; é preciso, para usá-lo em seu benefício, "seduzi-lo"; ele se torna a um só tempo objeto de cobiça e objeto de sedução, desejável, portanto, e isso na mesma medida em que ele é totalmente temível.

(...) O banal não podia ser dito, descrito, observado, enquadrado e qualificado senão em uma relação de poder que era assombrada pela figura do rei - por 
seu poder real e pelo fantasma de sua potência. Daí a forma singular desse discurso: ele exigia uma linguagem decorativa, imprecativa ou suplicante. Cada uma dessas pequenas histórias do dia-a-dia devia ser dita com a ênfase dos raros acontecimentos que são dignos de reter a atenção dos monarcas; a grande retórica devia vestir esses casos de nada. (Foucault, 2006, pp. 214-217)

Sejam, porém, guardadas as necessárias distinções, veementemente salientadas por Foucault, entre os sistemas jurídicos absolutistas e os contemporâneos. Segundo ele, "nunca, mais tarde, a morna administração policial nem os dossiês da Medicina ou da psiquiatria encontrarão semelhantes efeitos de linguagem" (2006, p. 217). As petições, anteriormente redigidas pela própria pessoa ou por um escriba leigo, hoje são confeccionadas pelo advogado, um profissional qualificado para o exercício do saber jurídico que representa, nos termos próprios, os interesses de alguém que pleiteia uma medida judicial, e isso perante um poder que não é personalizado, mas diluído no complexo de atribuições dispostas no código da lei e nas práticas da instituição judiciária.

O discurso que agora se produz, porém, embora apele para a neutralidade da razão e para os direitos fundamentais do ser humano, não é menos aliciador dos favores do juiz do que aquele outro o era, dos favores do rei. Aqui também o que se busca é seduzir o poder, atraí-lo de modo a se obter a medida judicial desejada, tanto assim que o mero exame dos autos costuma produzir no leitor certos sentimentos, mobilizar afetos e fantasias. É como se o discurso processual nos colocasse no centro da cena do litígio e de lá nos obrigasse a tomar partido por um ou outro litigante. Mais do que isso, o processo nos induz a questionar: "afinal de contas, quem está dizendo a verdade?" ou, "quem tem a razão?" Trata-se de uma verdadeira transferência processual, que mobiliza nossos sentimentos e fantasias e nos introduz em um conjunto de relações bem específico, regido pelos códigos judiciários característicos da sociedade disciplinar descrita por Foucault (1983). E é nesse "terreno", como diria Guirado " já marcado por uma estrutura de lugares, um imaginário e um objeto que lhe são característicos" (1995/2006, p. 120), que o perito se constitui.

Na justiça disciplinarizada, o juiz não julga sozinho: o ato do julgamento é dividido "entre diversas instâncias que devem, segundo se espera, medir, avaliar, diagnosticar, curar, transformar os indivíduos" (Foucault, 1983, p. 199). Entre outros agentes da instituição jurídica, peritos psicólogos e psiquiatras intervêm, antes da sentença, "não (...) para fazer um julgamento, mas para esclarecer a decisão dos juízes". (Foucault, 1983, p. 24).

A Psicologia, dessa forma, encontra-se implicada em um jogo triangular de produção de verdade e de razão, no qual pessoas em litígio se colocam à disposição da decisão de uma terceira instância, o Poder Judiciário, materializado na figura do juiz. E, em um lance desse jogo, não raro se recorre ao perito que, com a neutralidade que o discurso científico confere ao seu saber, deverá esclarecer os fatos a serem julgados pelo juiz. O perito ocupa, assim, um lugar estratégico no jogo de sedução do poder e da Justiça, pois é supostamente capaz de produzir a verdade que irá, finalmente, dissipar todas as dúvidas e justificar a medida judicial.

A inserção do psicólogo em processos nas Varas de Família e Sucessões do Brasil obedece a certas disposições do nosso Código de Processo Civil, ou Lei no 5869/73 (Brasil, 2005). A partir delas, define-se o lugar do perito como o de um auxiliar da Justiça que, assim como o escrivão, o oficial de Justiça, o depositário, o administrador e o intérprete, tem suas atribuições determinadas pelas normas de organização judiciária (CPC, art. 139). O perito é um profissional de nível universitário, 
devidamente inscrito em seu Conselho de classe, que entra em cena "quando a prova do fato depender de conhecimento técnico ou científico" (art. 145), ou seja, o perito é um produtor de prova pericial, que deverá juntar-se a outras provas para instruir uma decisão judicial.

Note-se que o texto da lei não se refere apenas ao psicólogo, mas a qualquer profissional de nível universitário, a depender do conhecimento necessário como base para a decisão judicial. É por isso que, segundo o artigo 420, "a prova pericial consiste em exame, vistoria ou avaliação". O Código ainda reza, em seu artigo 429:

Para o desempenho de sua função, podem o perito e os assistentes técnicos utilizar-se de todos os meios necessários, ouvindo testemunhas, obtendo informações, solicitando documentos que estejam em poder de parte ou em repartições públicas, bem como instruir o laudo com plantas, desenhos, fotografias e outras quaisquer peças.

O que acabamos de considerar não tem meramente um caráter informativo, mas é fundamental para que se compreenda qual é a posição das práticas da Psicologia jurídica no contexto que nos propomos estudar.

Os juízes de Varas de Família, em geral, determinam a realização de perícia psicológica para instruir suas decisões em processos (ou ações) judiciais que envolvem a guarda e/ou visitação de "menores" - crianças e adolescentes. Não são todos os processos dessa natureza, porém, que demandam a perícia psicológica, mas principalmente aqueles em que há uma demanda específica nesse sentido por parte de pelo menos um dos litigantes, ou nos quais as provas documentais e testemunhais não oferecem elementos suficientes para a formulação da sentença.
A leitura dos autos, que são preservados segundo o princípio de segredo de Justiça, é autorizada a um determinado perito quando há neles um ofício da autoridade judicial nesse sentido. Os autos configuram a cena processual e não devemos deixar de reconhecer que é essa mesma cena a que constitui os litigantes como partes, os advogados como seus representantes, e também o psicólogo como perito, permitindo a sua entrada em cena. Acreditamos que a leitura dos autos, formados por peças processuais de diversas origens, é um dos elementos mais importantes na análise da transferência na cena judiciária.

Em geral, a leitura faz com que o perito se depare com uma petição inicial que expõe a solicitação e os motivos do(a) requerente e, a seguir, com uma contestação que expõe os motivos do(a) requerido(a), assim como a sua defesa perante as pretensões do(a) requerente. Eventualmente, temos uma reconvenção quando o(a) requerido(a), com os mesmos argumentos de sua defesa, dá início a uma nova ação a partir da original e se torna reconvinte, enquanto o requerente se torna reconvindo e é provocado à contestação (artigos 315 a 318 do CPC); junto com eles, documentos e outras provas que se propõem a embasar os motivos e as pretensões de cada uma das partes. Agentes privilegiados da instituição judicial se fazem presentes nos despachos do juiz, nos pareceres dos promotores, nas informações do cartório e dos oficiais de Justiça, etc. É nesse cenário que a leitura dos autos nos coloca.

Todos esses textos têm como ponto de convergência principal os olhos e os ouvidos do juiz - exceto, é claro, os que ele mesmo produz. Em termos de análise institucional do discurso, diríamos que, na cena judiciária, o juiz é o ator, ou o lugar de locução, para o qual afluem todos os discursos enunciados no processo, sejam eles os das partes, os dos advogados, ou os dos agentes institucionais. 
Como peritos, auxiliares da Justiça, ainda que psicólogos, não podemos escapar totalmente dessa espécie de magnetismo processual, mas podemos compreendê-lo pelo recorte transferencial. É por isso que a leitura do processo deve ser, mais do que informativa, analítica.

Dessa forma, nossa leitura do processo não se restringe ao único objetivo de saber o que aconteceu com as partes pelas palavras que não são delas, mas de seus advogados. Também não tem, embora bastante instrutiva nesse sentido, o objetivo de nos ajudar a compreender os aspectos legais pertinentes ao caso, mas que são exteriores ao saber que nos compete. O que temos, efetivamente, que apreender é a demanda a nós formulada pela instituição judiciária, aquilo que se espera que nós, como peritos, façamos em um caso específico, para daí tomarmos as decisões pertinentes ao nosso próprio exercício profissional.

A partir da leitura dos autos, podemos decidir se responderemos ou não a essa demanda e, em caso positivo, de que lugar o faremos, entre os lugares possíveis para isso. Decidimos ainda como, quando e onde serão os encontros que teremos com os litigantes. Escolhemos quais serão as ferramentas teóricas e técnicas que, de acordo com a nossa formação e abordagem, serão as mais potentes para que se alcancem as finalidades próprias da Psicologia, ou seja, produzir os efeitos desejáveis tanto na amenização do sofrimento presente como na prevenção de danos maiores decorrentes do conflito judicial. Assim começamos a mover as peças do jogo processual de maneira distinta do Direito, embora ainda segundo suas regras. Nessa entrada em cena do psicólogo como perito, dois momentos são de crucial importância: a realização das entrevistas e a construção do laudo.

\section{A entrevista}

Se a entrada do perito de qualquer área de conhecimento na cena processual acontece a partir de uma determinação judicial, o modo como o psicólogo desenvolverá o seu trabalho nessa função tem a ver com uma competência que é própria da sua área de saber. É aqui que ele se reconhecerá, naquilo que faz parte da sua disciplina, e terá certo espectro de escolha para decidir a melhor maneira de conduzir o estudo do caso.

Os instrumentos de que dispomos para uma avaliação psicológica são a entrevista, individual ou grupal, e os testes psicológicos. Escolhemos, nesse artigo, nos debruçar sobre a entrevista, que é, sem dúvida, o instrumento mais utilizado por psicólogos de qualquer abordagem teórica. Até mesmo a aplicação de métodos projetivos, como o Rorschach e o TAT, continuam a exigir um exímio domínio de sua técnica.

Segundo Bleger, "a entrevista funciona como uma situação em que se observa parte da vida do paciente, que se desenvolve com relação a nós e diante de nós" (2007, p. 10). A análise institucional do discurso nos permite dizer que esse processo não ocorre de forma isolada das relações que são peculiares à instituição judiciária. O entrevistado não é aqui um paciente, mas alguém que demanda ou contesta uma possível demanda judicial; e a história de vida, que se desenvolve com relação a nós e diante de nós, é determinada pelas condições de produção da entrevista.

A entrevista coloca-nos em relação com uma parte do processo, seja qual for o estabelecimento ou espaço físico no qual aconteça: consultório - no caso do perito extrajudicial - ou o próprio fórum. Não é de admirar, portanto, que a pessoa se apresente a nós como a uma audiência. Ao invés da demanda que seria própria a um sujeito 
em busca de um atendimento psicológico, há uma demanda judicial na qual todos, inclusive o perito, estão enredados. O risco que corremos nesse momento é o de nos esquecermos de quem somos na cena - ou seja, peritos. Isso pode acontecer porque a nossa escuta é, geralmente, constituída no registro da clínica praticada nos consultórios.

Freud já havia apontado, em sua época, as diferenças entre os objetivos e métodos da psicanálise e os dos procedimentos destinados a provocar a confissão do criminoso no direito penal:

(...) no neurótico, o segredo está oculto de sua própria consciência; no criminoso, o segredo está oculto apenas dos senhores. No primeiro, existe uma autêntica ignorância, embora não em todos os sentidos, enquanto no último só existe uma simulação de ignorância. Com essa diferença, está em conexão uma outra que tem grande importância prática. Na psicanálise, o paciente ajuda a combater sua resistência através de esforços conscientes, porque espera lucrar com essa investigação, isto é, curar-se. O criminoso, ao contrário, não cooperará com o trabalho dos senhores; se o fizesse, estaria trabalhando contra todo o seu próprio ego. Entretanto, em compensação, em suas investigações, apenas os senhores necessitam obter uma convicção objetiva, ao passo que nossa terapia exige que o paciente também adquira essa mesma convicção. (Freud, 1976, p. 113)

A busca da determinação da veracidade, da simulação e da mentira no depoimento dos réus é marca importante da Psicologia e da psiquiatria penais. Foucault (2004a) mostra como os métodos de produção de verdade da psiquiatria (exame) e o do Direito penal (inquérito) se aproximaram para resolver a questão de como castigar os crimes sem razão, atos contra natura praticados por pessoas de cuja índole jamais se suspeitaria serem capazes das atrocidades que cometeram. Não bastava mais a confissão do crime, mas era necessário descobrir as suas razões:
Tendo o motivo do crime se tornado agora o motivo de punir, como punir, se o crime era sem motivo? Para punir se necessita saber qual é a natureza do culpado, sua insensibilidade, o grau de sua maldade, quais são seus interesses ou tendências.

(...) para que a mecânica punitiva possa funcionar, não basta a realidade da infração e de sua imputabilidade a um culpado; também é preciso estabelecer um motivo, digamos, uma relação psicologicamente inteligível entre o ato e o autor. (Foucault, 2004a, pp. 12-13)

No mesmo texto, Foucault também aponta uma importante contribuição do Direito civil ao Direito penal, que foi a introdução das noções de responsabilidade e de risco, seguidas da ideia de uma sanção ou tratamento voltado para a prevenção de futuros crimes. Além das razões subjetivas que levaram alguém a cometer um crime, era preciso, portanto, conhecer os riscos de que o criminoso viesse a reincidir. Assim surgiram os conceitos de imputabilidade e de periculosidade, importantes na determinação da pena ou da medida judicial a ser adotada.

O Direito de família, porém, acrescenta certas complicações a essas questões. O que está em questão não são os crimes cometidos por alguém, mas direitos que supostamente estão sendo lesados por um outro: o direito à guarda e à visita dos filhos, o direito a certos bens em uma partilha, etc. Dessa forma, as questões que se nos colocam são: existem realmente esses direitos? Foram de fato lesados? Qual é a medida judicial capaz de corrigir essa situação, ou seja, de restituir os direitos e as obrigações a quem de fato os detém? Quanto aos riscos, qual a melhor medida para prevenir suas consequências sobre as crianças e os incapazes?

No emaranhado de discursos que compõem a nossa demanda, empurrando-nos ora a inquirir, ora a examinar e, no fim de tudo, a produzir a prova pericial, ainda temos que 
nos haver com aquilo que compete à nossa própria disciplina, a Psicologia, constituinte da nossa experiência de sujeito.

Nesse nível é que se forma nossa sensibilidade - certos modos de olhar e de escutar - na relação com as pessoas que entrevistamos; as quais, por sua vez, trazem consigo suas próprias expectativas, suas demandas relativas a como devemos ser e a nos comportar na interação com elas. A maneira pela qual nós, peritos psicólogos, respondemos a tais demandas dependerá de como nos apropriamos do lugar que nos é destinado no âmbito da ação judiciária.

Nas relações que as partes estabelecem com o perito, atualizam-se os conflitos familiares que chegaram ao ponto limite de recorrer a uma ação judicial. Lidar com a transferência significa propor uma análise dos lugares que cada um dos entrevistados atribui a si mesmo e aos demais - ex-cônjuges, filhos e outros - envolvidos na lide, assim como das expectativas e dos afetos em jogo, quanto à medida judicial pleiteada ou refutada. $\mathrm{Na}$ medida em que procedemos às entrevistas, podemos melhor compreender a demanda de cada um dos envolvidos em relação ao Poder Judiciário e nos ressituar em relação à leitura inicial do processo.

Não podemos desconhecer o fato de que, não obstante toda a entrevista psicológica exigir certos cuidados técnicos e éticos em relação ao modo pelo qual o entrevistador conduz a si mesmo na relação que estabelece com o entrevistado, não se trata aqui de uma relação terapeuta-paciente. O enquadre ganha limites bem diferentes daqueles do consultório e, mesmo que o falar na primeira pessoa do singular, diante de um outro que escuta, provoque potenciais efeitos subjetivos - terapêuticos ou iatrogênicos aos quais devemos estar atentos, a entrevista será sempre, no contexto da perícia, destinada a produzir o laudo ou a prova, atravessada pelo conflito judicial.

Dizer isso, porém, não significa nos acomodarmos a simplesmente escutar as partes e executar aquilo que nos é determinado, sem qualquer crítica, mas deve levar-nos a reconhecer, em nossa atuação, os limites institucionais com os quais lidamos, limites esses que, diga-se de passagem, são inerentes a qualquer que seja o contexto de nossa atuação como psicólogos, tanto na clínica quanto na educação, na saúde, no trabalho ou na comunidade.

Entretanto é possível, ao longo das entrevistas, trabalhar as fantasias e as expectativas relativas aos lugares atribuídos pelas partes litigantes, graças à atualização, pela via da transferência, das histórias singulares e das relações que precederam a abertura do processo. Uma intervenção que leve em conta o elemento transferencial pode contribuir para que se produza, nas, e pelas, partes envolvidas, uma ressignificação dos conflitos familiares e da própria demanda judicial.

Um bom exemplo do que acabamos dizer é quando, ao longo do processo de perícia, uma acirrada disputa de guarda se transforma a ponto de o juiz ser deslocado de seu lugar de árbitro para se transformar em instância legitimadora de um acordo voluntário entre os antigos litigantes.

Percebe-se, assim, que a potência da entrevista psicológica como instrumento de estudo de caso e de intervenção é inegável. Todavia, o trabalho do perito-psicólogo não termina aqui, mas continua na produção de um documento que irá juntar-se aos autos como parte do conjunto de provas que instrumentará a sentença do juiz. Estamos falando do laudo, ou relatório psicológico. 


\section{O laudo pericial}

O laudo é a palavra do perito no jogo processual. É o momento em que ele assume a voz ativa perante todos os atores da cena jurídica. Esse momento é precedido por uma espécie de silêncio no compasso processual, que foi descrito por Caffé:

(...) diminuem-se drasticamente as comunicações nos autos dos processos (...). Há como que uma suspensão relativa da 'guerra processual' no terreno do fórum, no aguardo dos resultados do trabalho pericial (2003, p.75)

Se, até o laudo, o perito é designado pela voz do juiz, agora é ele quem diz a palavra da verdade, quem dá as suas cartas - sempre, é claro, tendo como interlocutor maior a autoridade judicial. Como peritos, porém, não falamos apenas ao juiz, mas a toda uma plateia composta por partes antagônicas, seus respectivos advogados e, em muitos casos, assistentes técnicos.

Uma atmosfera de ameaça envolve o perito no momento em que ele deve elaborar o laudo. Questionamentos de toda ordem, impugnações, ameaças de representação no Conselho de Psicologia: tudo isso compõe a cena na qual o perito toma a palavra. $\mathrm{O}$ laudo diz muito, portanto, do modo como o perito lida com a transferência processual.

De um lado, o laudo fala dos limites da função do psicólogo como perito; de outro, ele é potente e promove seus próprios fins. É preciso dar a devida importância ao que o laudo efetivamente é. Não se trata apenas da tradução e do resultado de um processo de avaliação psicológica, uma vez que esse relatório é peça processual ativa no conflito judicial. O laudo é um documento judicial. Mas isso não significa que ele deva ser formalmente idêntico a uma petição elaborada por um advogado, documento que, por definição, é sempre parcial, porque o perito está alinhado com o juiz na triangulação produzida pelo processo e, simultaneamente, deve responder aos preceitos éticos e científicos relativos à sua própria profissão.

Por seu alinhamento com a autoridade do juiz, e também por ser representativo da ciência psicológica, o discurso do perito deve ser impessoal, ou eivado de uma suposta neutralidade (vide artigo 138 do CPC). Qualquer venalidade no discurso do perito é coibida nesse contexto, a ponto de advogados - e assistentes técnicos - o escarafuncharem até o limite, em busca de qualquer indício de parcialidade ou falha, seja ela teórica, técnica, ética, ou até mesmo retórica.

Tal suposição de neutralidade é o que propicia que o laudo tenha uma função interventiva. Ele é, portanto, para o psicólogo jurídico, um momento crucial de seu processo de trabalho, não apenas por ser resultado de uma avaliação, mas, se tomamos o discurso - a partir da AID - como produtor de relações e subjetividades, por ser potencialmente analítico.

O laudo se torna analítico quando o psicólogo se apropria da palavra, que seu lugar de perito Ihe confere, para mostrar a complexidade dos vínculos familiares que levaram à transformação de um conflito particular em uma demanda judicial e o modo como isso interfere no andamento atual do processo. Os seus efeitos analíticos se fazem sentir quando ele se torna, por sua forma e conteúdo, uma intervenção que incide nos rumos a serem tomados pelos operadores do Direito - juízes, advogados e promotores - mostrando as possibilidades e os limites do processo e da medida judicial em cada situação específica.

Ao assumir, portanto, ser o portador de uma certa verdade, o psicólogo, como perito, deve avaliar todas as possíveis implicações e efeitos que o laudo pericial pode produzir 
no campo intersubjetivo que o processo configura. O laudo, muito mais que prova, é um documento que tem o potencial de levar as partes a se questionarem e a se reposicionarem em relação ao conflito. Esse potencial é ainda extensível aos agentes privilegiados do Direito - advogados, juízes e promotores de Justiça - permitindo que estes se apropriem de seus lugares e se deem conta dos efeitos de seus atos na cena processual.

Entretanto, pode-se também problematizar a real finalidade do laudo a partir do modo como ele é lido, especialmente por advogados mais interessados em ganhar suas causas do que na pacificação do litígio e na diminuição do sofrimento das pessoas neles envolvidas. Se o objetivo é destacar o que favorece e impugnar o que pode colocar em cheque os argumentos a favor da demanda do cliente, o resultado são entraves e embates que desgastam a relação entre o psicólogo e a instituição judiciária. É então que podemos nos questionar quanto ao valor interventivo que tentamos imprimir ao laudo. Não seria ele, nesse contexto, apenas mais um documento judiciário? Estando de tal forma sujeito às intempéries processuais, não cumpriria ele apenas finalidades alheias à nossa profissão e em relação às quais não temos a menor possibilidade de intervir?

Esse conflito, do qual não podemos escapar, é, a nosso ver, inerente ao próprio trabalho do psicólogo no contexto da instituição judiciária, e aponta para a necessidade de uma reflexão permanente quanto à busca de novos caminhos, tanto para a Psicologia como para o Direito.

\section{Para concluir}

A partir da análise institucional do discurso, esperamos ter mostrado, no presente texto, o entrecruzamento dos discursos que compõem a prática da perícia psicológica e, desse modo, destacado as suas linhas mestras. Falamos do discurso jurídico que determina a entrada do psicólogo na cena do processo. Essa entrada, porém, preserva de modo paradoxal uma relação de exterioridade entre os dois saberes, uma exterioridade tanto desejável quanto temida, uma vez que, como foi dito no início, produz conflito.

Quando analisamos a prática da perícia psicológica no nível dos discursos que a constituem e também daqueles que ela produz, nós nos damos conta de um tensionamento que não se restringe ao lugar atribuído ao perito na gestão dos conflitos familiares pelos meios jurídicos, ou à triangulação instaurada pelo processo judicial, mas também do encontro, nem sempre pacífico, entre saberes tão distintos quanto a Psicologia e o Direito.

O perito tem um papel importante na produção de provas e de verdade pela e para a instituição judicial, justamente porque as produz por meio de procedimentos alheios aos que são meramente jurídicos. Estes últimos, os procedimentos do perito, exigem uma expertise em relação à qual os demais agentes da cena judicial, incluindo juízes, promotores e advogados, são leigos. Ao mesmo tempo, ao introduzir outro saber na cena judiciária, o perito pode produzir efeitos nesse contexto que, de outro modo, não ocorreriam. Entre esses efeitos, citamos certa desordem na transferência processual, além de um desarranjo na triangulação entre partes e juiz. É aí que o saber próprio da Psicologia se torna potente e que a transferência processual pode ser apontada e elaborada.

O processo de avaliação psicológica pode ser considerado uma experiência que, além de constituir nosso fazer como psicólogos, tem um caráter singular, único para cada processo e que dificilmente é compartilhável ou traduzível nos termos do discurso jurídico. A instituição jurídica, por si mesma, não 
pode dar conta do que é dito diretamente ao perito durante as entrevistas. Essas falas, construídas a partir de histórias singulares, envolvem afetos, fantasias e expectativas que, ainda que atreladas ao processo, escapam ao alcance do saber judicial. E isso ocorre mesmo quando o discurso dos advogados que as representam transforma o que antes era um conflito familiar em conflito judicial.

Entretanto, não podemos escapar ao fato de que, por sua finalidade de produção de provas, o nosso trabalho está sujeito a disposições legais e judiciárias que formatam o nosso fazer de acordo com as normas jurídicas. O discurso do perito é, portanto, produto de toda uma série de contingências que atravessam a prática da Psicologia no âmbito judiciário.

A perícia, como prova judicial, afirma-se em uma certa vontade de verdade característica da instituição jurídica e, ao mesmo tempo, na intenção do perito de, como coadjuvante da cena processual, nela produzir efeitos singulares. É importante que a tomada da palavra pelo perito na produção do laudo acentue que o que se está produzindo não é a Verdade, mas uma verdade relativa, a atribuição de um sentido possível ao conflito configurado no processo.

Esperamos que uma reflexão dessa natureza nos induza a reinventar a prática da Psicologia a cada novo processo judicial, ao invés de simplesmente nos contentarmos em reeditála em um contexto claramente adverso, buscando imprimir ao nosso fazer como peritos um sentido que ele jamais teria se fosse realizado de maneira meramente burocrática.

Se refletir sobre o nosso trabalho muitas vezes nos coloca face a face com os limites - e entraves - que a instituição judiciária impõe ao exercício pacífico de nossa profissão, não podemos nos esquecer de que é exatamente a consciência desses limites que pode induzirnos a criar estratégias de subversão dos destinos do processo judicial. Ao tornarmos visível e audível aos olhos e ouvidos dos agentes judiciários, bem como das partes envolvidas, o jogo transferencial implícito no processo, à medida que iluminamos suas amarras discursivas, propomos um caminho que pode ir além dos desejos de retaliação e da aplicação fria da lei. 


\section{Marta Cristina Meirelles Ortiz}

Mestre e Doutora em Psicologia Escolar e do Desenvolvimento Humano pela Universidade de São Paulo. Docente do Curso de Psicologia da Universidade Federal de São Paulo - Campus Baixada Santista, Santos - SP - Brasil. E-mail:marta.ortiz@unifesp.br

Endereço para envio de correspondência:

Rua Liberdade, 179, Ap. 32. Boqueirão, Santos -SP. CEP: 11025-030

Recebido 28/03/2011, 1a Reformulação 26/03/2012, Aprovado 18/10/2012. 
Bleger, J. (2007). Temas de psicologia: entrevistas e grupos. São Paulo: Martins Fontes.

Brasil. (2005). Código de Processo Civil: legislação complementar. São Paulo: IOB -Thomson/Universidade Estácio de Sá.

Caffé, M. (2003). Psicanálise e direito. São Paulo: Quartier Latin.

Conselho Federal de Psicologia. (2010). Referências técnicas para atuação do psicólogo nas Varas de Família / Conselho Federal de Psicologia. Brasília, DF: Autor.

Conselho Federal de Psicologia. (2010). Resolução no 08/2010. Brasília, DF: Autor. Recuperado em 10 de março, 2012 de http:// nuria-sandplay.blogspot.com.br/2010/07/resolucao-cfp-n082010peritos-e.html.

Conselho Regional de Psicologia da 6a. Região. (Org.). (2010). Psicólogo judiciário nas relações de família. A ética própria da psicologia: mudanças na relação assistente técnico e perito. São Paulo: Autor.

Freud, S. (1976). A psicanálise e a determinação dos fatos no processo jurídico. In Edição standard brasileira das obras psicológicas completas de S. Freud (J. Salomão, trad., Vol. 9, pp. 100-115). Rio de Janeiro: Imago (Trabalho original publicado em 1906).

Freud, S. (2010). A dinâmica da transferência. In Obras completas (Vol. 10, p.131-146). São Paulo: Companhia das Letras. (Trabalho original publicado em 1912).

Foucault, M. (1983). Vigiar e punir: história da violência nas prisões. Petrópolis, RJ: Vozes (Trabalho original publicado em 1975).

Foucault, M. (2004a). A evolução da noção do "indivíduo perigoso" na psiquiatria legal do século XIX. In Ética, sexualidade, política (Coleção Ditos \& Escritos, Vol. 5, pp. 1-25). Rio de Janeiro: Forense Universitária (Trabalho original publicado em 1978).

Foucault, M. (2004b). A ética do cuidado de si como prática da liberdade. In Ética, sexualidade, política (Coleção Ditos \& Escritos, Vol. 5, pp. 264-287). Rio de Janeiro: Forense Universitária (Trabalho original publicado em 1984).

Foucault, M. (2006). A vida dos homens infames. In Estratégia, poder-saber (Coleção Ditos \& Escritos, Vol. 4, 2a. ed., pp. 203222). Rio de Janeiro: Forense Universitária (Trabalho original publicado em 1977).

Guirado, M. (2000). A clínica psicanalítica à sombra do discurso: diálogos com aulas de Dominique Maingueneau. São Paulo: Casa do Psicólogo.

Guirado, M. (2004). Psicologia institucional (2a. ed. revista e ampliada.) São Paulo: EPU. (Trabalho original publicado em 1987).

Guirado, M. (2006). Transferência e transferências. In M. Guirado, Psicanálise e análise do discurso: matrizes institucionais do sujeito psíquico (2a. ed. revista e ampliada.) São Paulo: EPU (Trabalho original publicado em 1995).

Guirado, M. (2009). A análise institucional do discurso como analítica da subjetividade. Tese Livre Docência. Instituto de Psicologia da Universidade de São Paulo, SP.

Guirado, M. (2010). A análise institucional do discurso como analítica da subjetividade. São Paulo: Annablume. 